\title{
Numerical Models for Coastal Zone Management
}

\author{
J. Cardona
}

$\&$

A. Samartin

\begin{abstract}
The basic equations for modelling two-dimensional hydrodynamics and transport in estuaries and coastal regions have been developed. By using the finite element method, it is possible to transform the model into a discretized counterpart. The model has been applied in order to study the dispersion of an effluent within the Bay of Santander. The results obtained by means of a computer program are discussed.
\end{abstract}

\section{INTRODUCTION}

The increasing size of urban populations located in coastal areas, and the corresponding increase in the amount of waste disposed in rivers and estuaries, led to studies concerning the water quality in these areas.

Pollutants such as radioactive substances, toxic substances, heat discharges, etc. ${ }^{1}$ are introduced into the water through various diffusors. ${ }^{2,3}$ Some of these pollutants may react among themselves. ${ }^{4-6}$

There are several procedures to study the quality of a given water sample at a given instant, when a set of specified pollutant diffusors exist: physical models, ${ }^{7,8}$ statistical correlations, ${ }^{9}$ the use of tracers ${ }^{10,11}$ and numerical methods among others. Numerical methods are probably the most economical. In this respect, there are two main techniques, namely, the finite differences and the finite element method (FEM). The relative advantages of both procedures have been discussed elsewhere. ${ }^{12-16}$ The FEM procedure is considered in this paper.

FEM has been discussed by several authors. ${ }^{16-18}$ In this paper, only 
the main results are presented. Two principal mathematical models are required in order to simulate the pollutant dispersion in estuaries and coastal zones: the hydrodynamic model and the transport model. For the sake of simplicity, both models are described for a two-dimensional space.

\section{THE HYDRODYNAMIC MODEL}

\subsection{Principal equations}

Figure 1 shows the geometry of a typical cross-section of an estuary. Because the estuary is assumed to have an arbitrary bathymetry, $h$, the distance from mean sea level to the bed of the estuary is a function of $x$, $y$. Moreover, due to the tidal motion, the surface elevation from mean sea level $\xi$ is a function of time as well as $x, y$. The total distance from the bed of the estuary to the surface is denoted by $H$ where

$$
H(x, y)=h(x, y)+\xi(x, y, t)
$$

The development presented below follows the same lines as that of Pritchard. ${ }^{19}$ A set of equations appropriate for areal modelling of vertically well-mixed water bodies is obtained by averaging the threedimensional equations over depth. It is further assumed that the fluid density is constant.

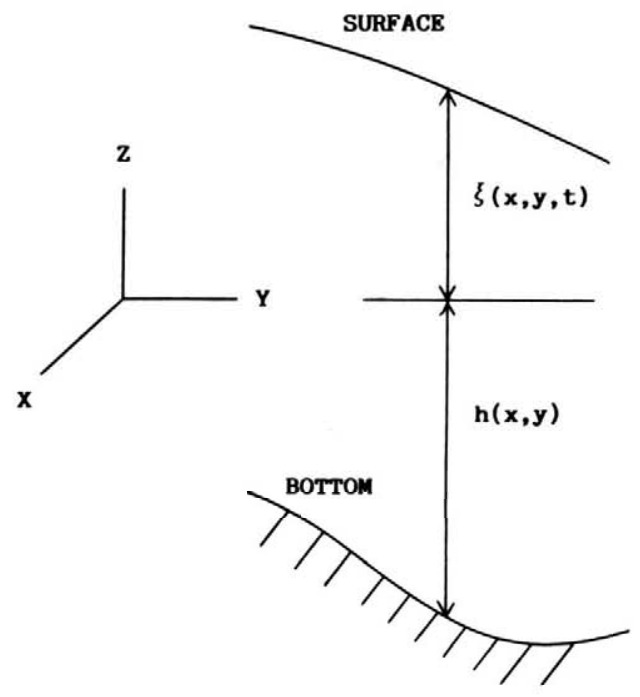

Fig. 1. Geometry. 
The results to be obtained from the hydrodynamic model are: the surface elevation $\xi$, and the two velocity components $U$ and $V$, which are averaged through depth. These three kinds of results have to be computed for each point $(x, y)$ and time $t$; and they are used as input data for the second model, the transport model.

Two types of equations are used in the hydrodynamic model, namely, the continuity equation and the momentum equations.

The three-dimensional continuity equation is

$$
\frac{\mathrm{D} M}{\mathrm{D} t}=\frac{\mathrm{D}}{\mathrm{D} t} \int_{V} \rho \mathrm{d} V=0
$$

where $M$ is the total mass existing in the volume element $V$ and $\rho$ is the water density, and $\mathrm{D} / \mathrm{D} t$ is the total derivative with respect to time $t$.

Averaging eqn (2) through the sea depth $H$, the following result is obtained

$$
\frac{\delta H}{\delta t}+\frac{\delta(H U)}{\delta x}+\frac{\delta(H V)}{\delta y}=0
$$

where $U$ and $V$ are the mean velocities given by the following expressions

$$
U=\frac{1}{H} \int_{-h}^{\xi} u \mathrm{~d} z ; \quad V=\frac{1}{H} \int_{-h}^{\xi} v \mathrm{~d} z
$$

where $u$ and $v$ are the particle velocity components.

Newton's law can be expressed by

$$
\int_{V} \rho \mathbf{b} \mathrm{d} V+\int_{S} \mathbf{p} \mathrm{d} S=\frac{\mathrm{D}}{\mathrm{D} t} \int_{V} \rho \mathbf{v} \mathrm{d} V
$$

The external actions are represented by a distributed surface force, $\mathbf{p}$ per unit surface area, and a distributed body force, $b$ per unit mass.

For application of Gauss' integration formula to eqn (5), the following equation is obtained

$$
\frac{\delta \rho v_{i}}{\delta t}+\frac{\delta \rho v_{i} v_{j}}{\delta x_{j}}=\frac{\delta \sigma_{i j}}{\delta x_{j}}+\rho b_{i}
$$

where $i=1,2,3$, correspond to $x, y, z$, and $\sigma_{i j}$ are the vector components of the stresses $\left(\sigma_{i j}=\sigma_{j i}\right)$.

The values of $\boldsymbol{\sigma}_{i j}$ can be expressed as the sum of a pressure term plus a friction term i.e.

$$
\sigma_{i j}=-p \delta_{i j}+\tau_{i j}
$$

where $p$ is the hydrostatic pressure; $\tau_{i j}$ is the friction stress; and $\delta_{i j}$ is the Kronecker delta $\left(\delta_{i j}=0 i \# j ; \delta_{i i}=1\right)$. 
Introducing the assumptions that the vertical acceleration is null, and that the two components of the shear stresses are negligible in comparison to the gravity stresses, eqn (6) in the vertical direction can be replaced by the following

$$
\frac{1}{\rho}\left(\frac{\delta p}{\delta z}\right)+g=0
$$

i.e.

$$
p=p_{\mathrm{A}}+\rho g(\xi-z)
$$

where $p_{\mathrm{A}}$ is the atmospheric pressure and $g$ is the gravity acceleration.

Introducing eqn (9) in the two remaining eqns (6) and averaging them through the depth of the area, $H$, the following bidimensional equations are obtained

$$
\begin{aligned}
& \frac{\delta U}{\delta t}+U \frac{\delta U}{\delta x}+V \frac{\delta U}{\delta y}-f V+g \frac{\delta \xi}{\delta x}-K \frac{W^{2}}{H} \cos \beta+g U \frac{\left(U^{2}+V^{2}\right)^{1 / 2}}{H C^{2}}=0 \\
& \frac{\delta V}{\delta t}+U \frac{\delta V}{\delta x}+V \frac{\delta V}{\delta y}+f U+g \frac{\delta \xi}{\delta y}-K \frac{W^{2}}{H} \sin \beta+g V \frac{\left(U^{2}+V^{2}\right)^{1 / 2}}{H C^{2}}=0
\end{aligned}
$$

where the terms due to eddy viscosity have been neglected, ${ }^{20}$ and $f$ is the Coriolis parameter. $K$ is a dimensionless coefficient function of the wind velocity $W,{ }^{20}$ and $\beta$ is the angle of the wind velocity vector with the $X$-axis; and $C$ is the Chezy coefficient (dimensions length ${ }^{1 / 2} /$ time). $^{2}$

\subsection{Finite element model}

In the FEM each variable is expanded in terms of a discrete set of functions $\phi_{j}(x, y)$ and nodal values $\xi_{j}(t), U_{j}(t), V_{j}(t), h_{j}, f_{j}, K_{j}, W_{j}, \beta_{j}$

$$
\begin{gathered}
U=\sum_{j=1}^{N} U_{j}(t) \phi_{j}(x, y) \quad V=\sum_{j=1}^{N} V_{j}(t) \phi_{j}(x, y) \\
\xi=\sum_{j=1}^{N} \xi_{j}(t) \phi_{j}(x, y) \quad h=\sum_{j=1}^{N} h_{j} \phi_{j}(x, y) \\
f=\sum_{j=1}^{N} f_{j} \phi_{j}(x, y) \\
K W^{2} \cos \beta=\left[K_{j} W_{j}^{2} \sin \beta_{j}\right] \phi_{j}(x, y) \\
K W^{2} \sin \beta=\left[K_{j} W_{j}^{2} \sin \beta_{j}\right] \phi_{j}(x, y)
\end{gathered}
$$

where, $N$ is the number of nodes in the finite element domain. 
Substitution of eqn (11) into eqns (3) and (10) and application of Galerkin procedure, gives the following set

$$
\begin{aligned}
M \dot{\xi} & =\mathbf{E}_{\mathbf{\xi}} \\
M \dot{U} & =\mathbf{E}_{\mathbf{u}} \\
M \dot{\mathbf{V}} & =\mathbf{E}_{\mathbf{v}}
\end{aligned}
$$

where the unknowns are

$$
\begin{aligned}
\xi & =\left(\xi_{1}, \xi_{2}, \ldots, \xi_{N}\right) t \\
\mathbf{U} & =\left(U_{1}, U_{2}, \ldots, U_{N}\right) t \\
\mathbf{V} & =\left(V_{1}, V_{2}, \ldots, V_{N}\right) t
\end{aligned}
$$

and, using the Einstein convention

$$
\begin{aligned}
E_{\xi_{i}}= & -\left(B_{x i j k}+B_{x i k j}\right)\left(h_{j}+\xi_{j}\right) U_{k}-\left(B_{y i j k}+B_{y i k j}\right)\left(h_{j}+\xi_{j}\right) V_{k} \\
E_{U_{i}}= & -B_{x i j k} U_{j} U_{k}-B_{y i j k} U_{j} V_{k}+C_{i j k} V_{j} f_{k}-g D_{x i j} \xi_{j} \\
& -g F_{i j} U_{j}+G_{i j} K_{j} W_{j}^{2} \cos \left(\beta_{j}\right) \\
E_{V_{i}}= & -B_{x i j k} V_{j} U_{k}-B_{y i j k} V_{j} V_{k}-C_{i j k} U_{j} f_{k}-g D_{y i j} \xi_{j} \\
& -g F_{i j} V_{j}+G_{i j} K_{j} W_{j}^{2} \sin \left(\beta_{j}\right)
\end{aligned}
$$

with

$$
\begin{array}{cc}
M_{i j}=\int_{A} \phi_{i} \phi_{j} \mathrm{~d} A ; & B_{x i j k}=\int_{A} \phi_{i} \frac{\delta \phi_{j}}{\delta x} \phi_{k} \mathrm{~d} A \\
B_{y i j k}=\int_{A} \phi_{i} \frac{\delta \phi_{j}}{\delta y} \phi_{k} \mathrm{~d} A ; & C_{i j k}=\int_{A} \phi_{i} \phi_{j} \phi_{k} \mathrm{~d} A \\
D_{x i j}=\int_{A} \phi_{i} \frac{\delta \phi_{j}}{\delta x} \mathrm{~d} A ; & D_{y i j}=\int_{A} \phi_{i} \frac{\delta \phi_{j}}{\delta y} \mathrm{~d} A \\
F_{i j}=\int_{A} \frac{\phi_{i} \phi_{j}\left[\left(\sum U_{k} \phi_{k}\right)^{2}+\left(\sum V_{k} \phi_{k}\right)^{2}\right]^{1 / 2}}{C^{2} \sum\left(\xi_{k}+h_{k}\right) \phi_{k}} \mathrm{~d} A ; & G_{i j}=\int_{A} \frac{\phi_{i} \phi_{j}}{\sum\left(\xi_{k}+h_{k}\right) \phi_{k}} \mathrm{~d} A
\end{array}
$$

The set (12) of simultaneous first order differential equations is non-linear, because the coefficients $F_{i j}$ and $G_{i j}$ depend on the unknown $\xi_{j}, U_{j}$ and $V_{j}$. The matrix $\boldsymbol{M}$ is a function of the element geometry only. The central task is, therefore, that of integrating in time a set of coupled eqns (12) for the nodal values, from given initial conditions and subject to specified boundary constraints.

The time derivatives may be approximated by finite differences over 
an interval $\Delta t$, then

$$
\begin{gathered}
M \xi_{(t+\Delta t)}=M \xi_{(t)}-\frac{\Delta t}{2}\left[\mathbf{E}_{\xi(t+\Delta t)}+\mathbf{E}_{\xi(t)}\right] \\
M \mathbf{U}_{(t+\Delta t)}=M \mathbf{U}_{(t)}-\frac{\Delta t}{2}\left[\mathbf{E}_{U(t+\Delta t)}+\mathbf{E}_{U(t)}\right] \\
M \mathbf{V}_{(t+\Delta t)}=M \mathbf{V}_{(t)}-\frac{\Delta t}{2}\left[\mathbf{E}_{V(t+\Delta t)}+\mathbf{E}_{V(t)}\right]
\end{gathered}
$$

Using a step-by-step procedure, and through iteration in each time interval $\Delta t$ (because the values of the functions in the right hand side at $t+\Delta t$ are unknowns), it is possible to find the vectors $\mathbf{U}, \mathbf{V}$ and $\xi$ at each instant.

Besides the initial conditions, i.e. at time $t=0$, two types of boundary conditions can be considered:

(a) A fixed boundary along the coastline.

(b) An open boundary defined by a fictitious line, corresponding to the separation between the open sea or the river delta, and the estuary.

In both cases, the specified values of $\xi, U$ and $V$ must be introduced in the analysis at each time interval. In this respect, the techniques to be used correspond to the manipulation of the matrices $\boldsymbol{M}$ and the vectors $\mathbf{E}$, without destroying the symmetry of the problem as occurs in the matrix analysis of structures.

\section{TRANSPORT MODEL}

\subsection{Main equations}

From the classical formulation of the 3-D general differential equations of molecular diffusion, it is possible to deduct the 2-D equation of this problem by averaging through the sea depth.

In this way, the following 2-D transport equation is obtained

$$
\begin{aligned}
\rho C H\left(\frac{\delta \theta}{\delta t}\right)+ & \rho H U \frac{\delta \theta}{\delta x}+\rho H V \frac{\delta \theta}{\delta y}=-\alpha H \theta+\rho H F_{1}+\rho F_{2} \\
& +\sum Q_{k} \delta_{k}+C \frac{\delta}{\delta x}\left[H D_{x} \frac{\delta \theta}{\delta x}\right]+\rho C \frac{\delta \theta}{\delta y}\left[H D_{y} \frac{\delta \theta}{\delta y}\right]
\end{aligned}
$$


where $\rho$ is the constant fluid density; $\theta$ is the concentration of pollutant; $H$ is the total depth of the sea; $U$ and $V$ are components of the velocity; $C$ is a constant $(C=1$ in mass transfer problems; $C=$ specific heat, in heat transfer problems); the point, surface and volume sources of contaminant are included in the terms $\sum Q_{k} \delta_{k}, F_{2}$ and $F_{1}$ respectively; $\alpha$ is a decay coefficient due to a hypothetical reaction of the pollutant; and $D_{x}$ and $D_{y}$ are the dispersivities in the directions $x$ and $y$. It is assumed that the dispersion is not necessarily isotropic.

Only two boundary conditions are considered (the estuary boundary is $\delta A=\delta A_{1}+\delta A_{2}$ )

$$
\begin{aligned}
& \text { (a) }\left.\theta\right|_{\delta A_{1}}=\bar{\theta} \\
& \text { (b) }-\left.\rho C D_{n} \frac{\delta \theta}{\delta n}\right|_{\delta A_{2}}=\bar{q}_{n}
\end{aligned}
$$

where, $\bar{\theta}$ and $\bar{q}_{n}$ are given values of the concentration (or temperature) and of the flux normal to the boundary; $D_{n}$ is the dispersivity along this normal direction.

The initial condition, i.e. pollutant concentration at time $t=0$, must also be given as data.

\subsection{Finite element model}

The known values of $U, V$ and $H$ are approximated as follows

$$
\begin{gathered}
U=\sum_{i=1}^{N} U_{i} \phi_{i} \\
V=\sum_{i=1}^{N} V_{i} \phi_{i} \\
H=\sum_{i=1}^{N} H_{i} \phi_{i}
\end{gathered}
$$

The unknown concentration $\theta$ is also described by the interpolant functions $\phi_{1}$

$$
\theta=\sum_{i=1}^{N} \theta_{i} \phi_{i}
$$

Using the technique of Galerkin, the discretized counterpart of the eqn (17) is

$$
\boldsymbol{M} \dot{\boldsymbol{\theta}}+(\boldsymbol{K}+\boldsymbol{A}+\boldsymbol{B}) \boldsymbol{\theta}=\boldsymbol{P}
$$


where

$$
\begin{aligned}
\theta & =\left(\theta_{1}, \theta_{2}, \ldots, \theta_{N}\right) \\
M_{i j} & =\int_{A} \rho H \phi_{i} \phi_{j} \mathrm{~d} A \\
K_{i j} & =\int_{A} \rho C H D_{k}\left(\frac{\delta \phi_{i}}{\delta x_{k}}\right)\left(\frac{\delta \phi_{j}}{\delta x_{k}}\right) \mathrm{d} A \\
A_{i j} & =\int_{A} \rho C H V_{k}\left(\frac{\delta \phi_{i}}{\delta x_{k}}\right) \phi_{j} \mathrm{~d} A \\
B_{i j} & =\int_{A} \rho C \alpha H \phi_{i} \phi_{j} \mathrm{~d} A \\
P_{i j} & =\int_{A} F \phi_{j} \mathrm{~d} A-\sum Q_{k} \phi_{j} \delta_{k}+\int_{\delta A_{2}} H \bar{q}_{n} \phi_{j} \mathrm{~d} s
\end{aligned}
$$

Equation (21) can be integrated by means of the trapezoidal scheme,${ }^{21}$ leading to

$$
\frac{2}{\Delta t}(\boldsymbol{M}+\boldsymbol{K}+\boldsymbol{A}+\boldsymbol{B}) \boldsymbol{\theta}_{(t+\Delta t)}=\frac{2}{\Delta t}(\boldsymbol{M}-\boldsymbol{K}-\boldsymbol{A}-\boldsymbol{B}) \boldsymbol{\theta}_{(t)}+2 \mathbf{P}
$$

Introducing the boundary conditions, the linear set of simultaneous algebraic equations can be solved by a direct method, ${ }^{22,23}$ and the unknowns $\theta$ can be obtained at each instant.

\subsection{Numerical tests}

The transport model has been applied to some simple cases in order to assess the numerical efficiency and degree of accuracy of the numerical method used.

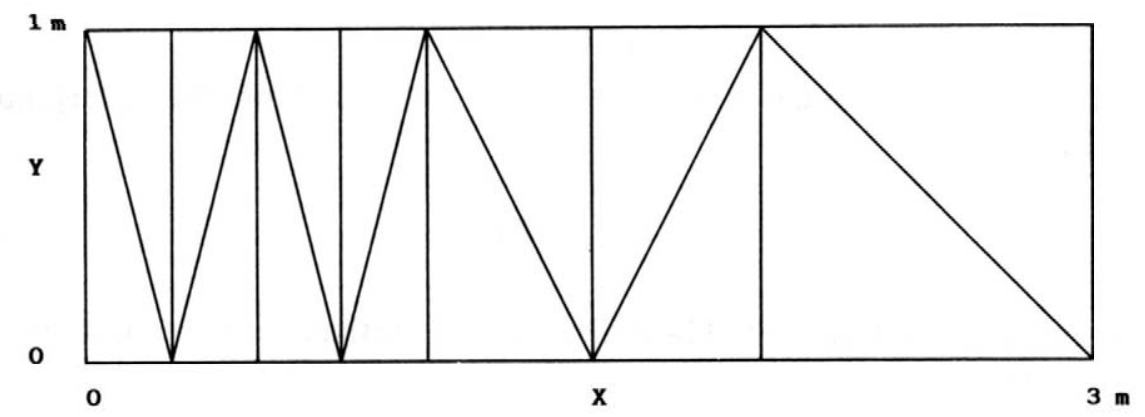

Fig. 2. Finite element mesh (Case 1). 
TABLE 1

Data of Case 1

\begin{tabular}{|c|c|c|c|c|c|c|}
\hline \multicolumn{2}{|c|}{$\begin{array}{l}\text { Velocity } \\
\left(\mathrm{m} / \mathrm{s}^{-1}\right)\end{array}$} & \multicolumn{2}{|c|}{$\begin{array}{l}\text { Dispersion coefficient } \\
\qquad\left(m^{2} s^{-1}\right)\end{array}$} & \multirow{2}{*}{$\begin{array}{c}\text { Depth } \\
(m) \\
h\end{array}$} & \multicolumn{2}{|c|}{$\begin{array}{c}\text { Concentration } \\
\rho_{1} / \rho\end{array}$} \\
\hline$U$ & $V$ & $D_{x}$ & $D_{y}$ & & $\theta(x=0)$ & $\theta(t=0)$ \\
\hline 0.05 & 0.00 & 0.01 & 0.00 & $1 \cdot 00$ & 1.00 & 0.00 \\
\hline
\end{tabular}

\subsubsection{Case 1}

This corresponds to the wave propagation along the channel shown in Fig. 2. It is assumed that the material concentration is known along the initial border, and that the velocity distribution of the fluid is uniform. The data are given in Table 1 . The FEM mesh used to find the numerical solution is also shown in Fig. 2. It is composed of 14 linear strain triangles (LST), and 45 nodes. The elements have been concentrated near the input edge, in order to better represent the changes in the concentration.

The stationary solution is given in Table 2 . The transitory solution has been obtained for different time-steps $\Delta t$. The result for $\Delta t=\frac{1}{4} \mathrm{~s}$ is shown in Fig. 3. The numerical solution appears to be underestimated for small values of $\Delta t$ and in the regions with least number of nodes. The closed form solution for this case is the following function

$$
\theta(x, t)=\frac{1}{2} \operatorname{erfc}\left[\frac{x-u t}{2\left(D_{x} t\right)^{1 / 2}}\right]+\frac{1}{2} e^{u x / D_{x}} \cdot \operatorname{erfc}\left[\frac{x+u t}{2\left(D_{x} t\right)^{1 / 2}}\right]
$$

TABLE 2

Concentration

\begin{tabular}{ccc}
\multicolumn{3}{c}{ Concentration } \\
\hline \multicolumn{3}{c}{ Stationary case } \\
\hline Position & $F E$ solution & Analytic solution \\
$X(m)$ & $\theta\left(\rho_{1} / \rho\right)$ & $\theta\left(\rho_{1} / \rho\right)$ \\
\hline 0.000 & 1.0000 & 1.0000 \\
0.125 & 1.0000 & $1 \cdot 0000$ \\
0.250 & 1.0000 & 1.0000 \\
0.375 & 1.0000 & $1 \cdot 0000$ \\
0.500 & 1.0000 & 1.0000 \\
0.625 & 1.0000 & 1.0000 \\
0.750 & 1.0000 & $1 \cdot 0000$ \\
0.875 & 1.0000 & 1.0000 \\
1.000 & 1.0000 & 1.0000 \\
\hline
\end{tabular}




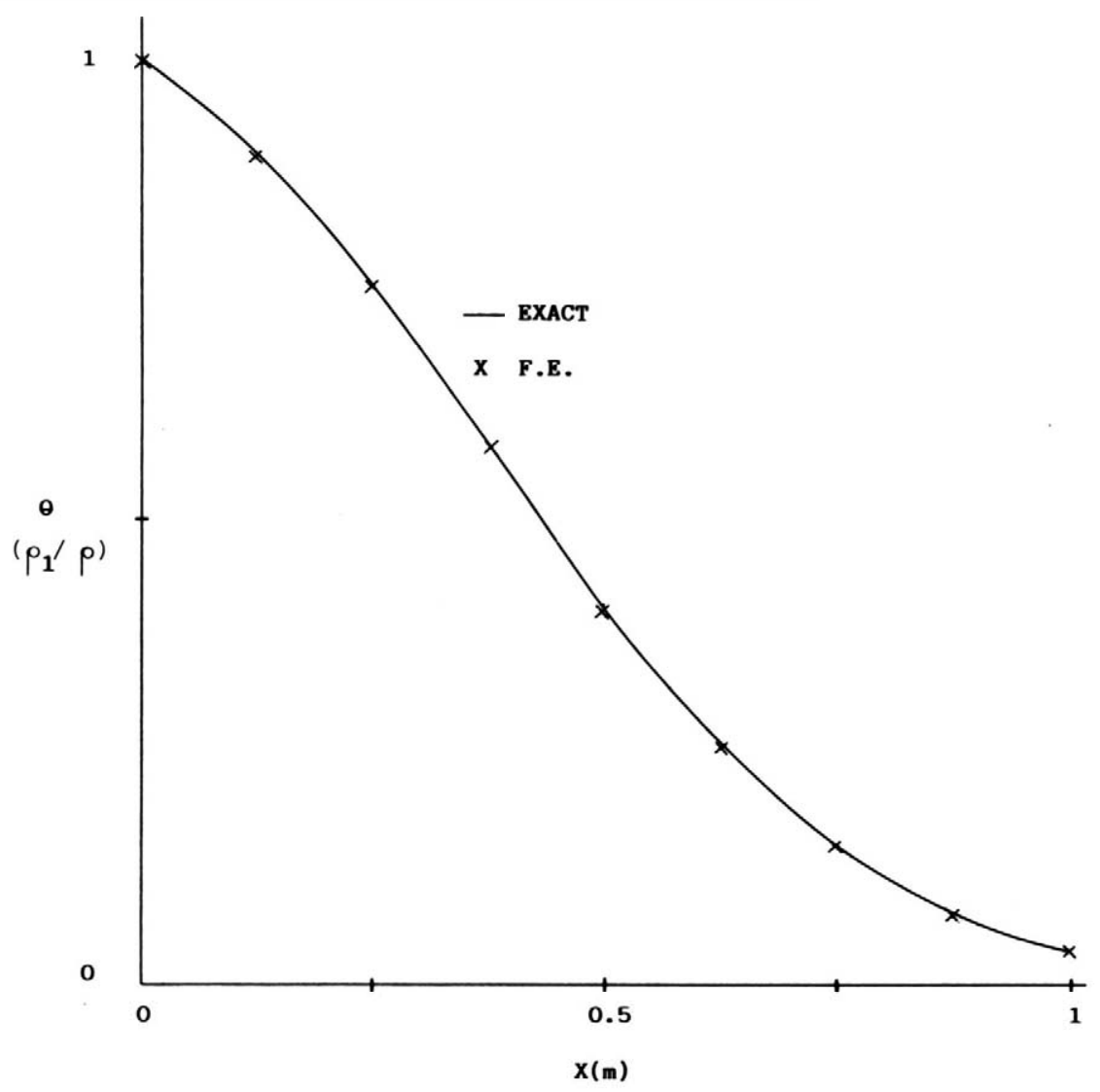

Fig. 3. Concentration profile for $t=6 \mathrm{~s} ; \Delta t=0.25 \mathrm{~s} ;\left(D_{x}, D_{y}\right)=(0.01,0 \cdot 0) \mathrm{m}^{2} \mathrm{~s}^{-1}$; $(u, v)=(0 \cdot 05,0 \cdot 0) \mathrm{m} \mathrm{s}^{-1}$.

\subsubsection{Case 2}

This corresponds to the transport of material along the channel shown on Fig. 4, with pollutant input along the straight line $x=x_{k}$. Different decay coefficients $\alpha$ have been assumed. Data used in this case are listed in Table 3. The FEM mesh contains 28 LST elements and 87 nodes.

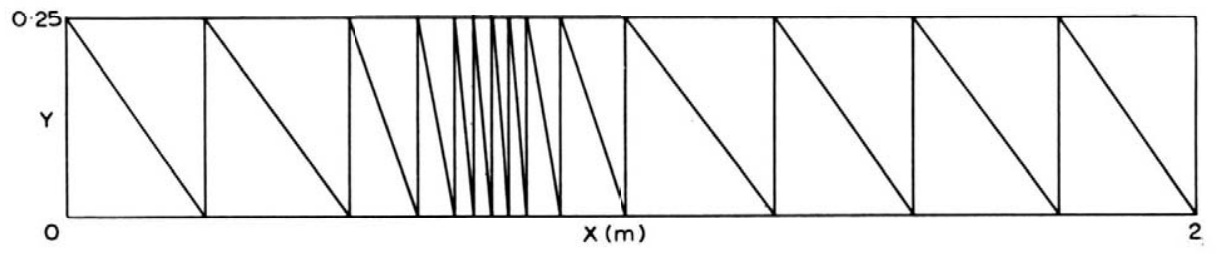

Fig. 4. Finite element mesh (Case 2). 
TABLE 3

Data of Case 2

\begin{tabular}{|c|c|c|c|c|c|c|c|c|c|}
\hline \multicolumn{2}{|c|}{$\begin{array}{l}\text { Velocity } \\
\left(\mathrm{ms}^{-1}\right)\end{array}$} & \multicolumn{2}{|c|}{$\begin{array}{l}\text { Disp. coef. } \\
\quad\left(m^{2} s^{-1}\right)\end{array}$} & \multirow{2}{*}{$\begin{array}{c}\text { Depth } \\
(\boldsymbol{m}) \\
H\end{array}$} & \multirow{2}{*}{$\begin{array}{c}\text { Domain } \\
(m) \\
\Omega\end{array}$} & \multicolumn{3}{|c|}{$\begin{array}{l}\text { Nodal disch. } \\
\quad\left(s^{-1}\right)\end{array}$} & \multirow{2}{*}{$\begin{array}{c}\text { Position } \\
(m) \\
x_{k}\end{array}$} \\
\hline$U$ & $V$ & $D_{x}$ & $D_{y}$ & & & $Q_{37}$ & $Q_{38}$ & $Q_{39}$ & \\
\hline $0 \cdot 1$ & 0.0 & $0 \cdot 01$ & 0.00 & $1 \cdot 0$ & {$[0,2] \times\left[0, \frac{1}{4}\right]$} & $\frac{1}{6}$ & $\frac{2}{3}$ & $\frac{1}{6}$ & $\frac{3}{4}$ \\
\hline
\end{tabular}

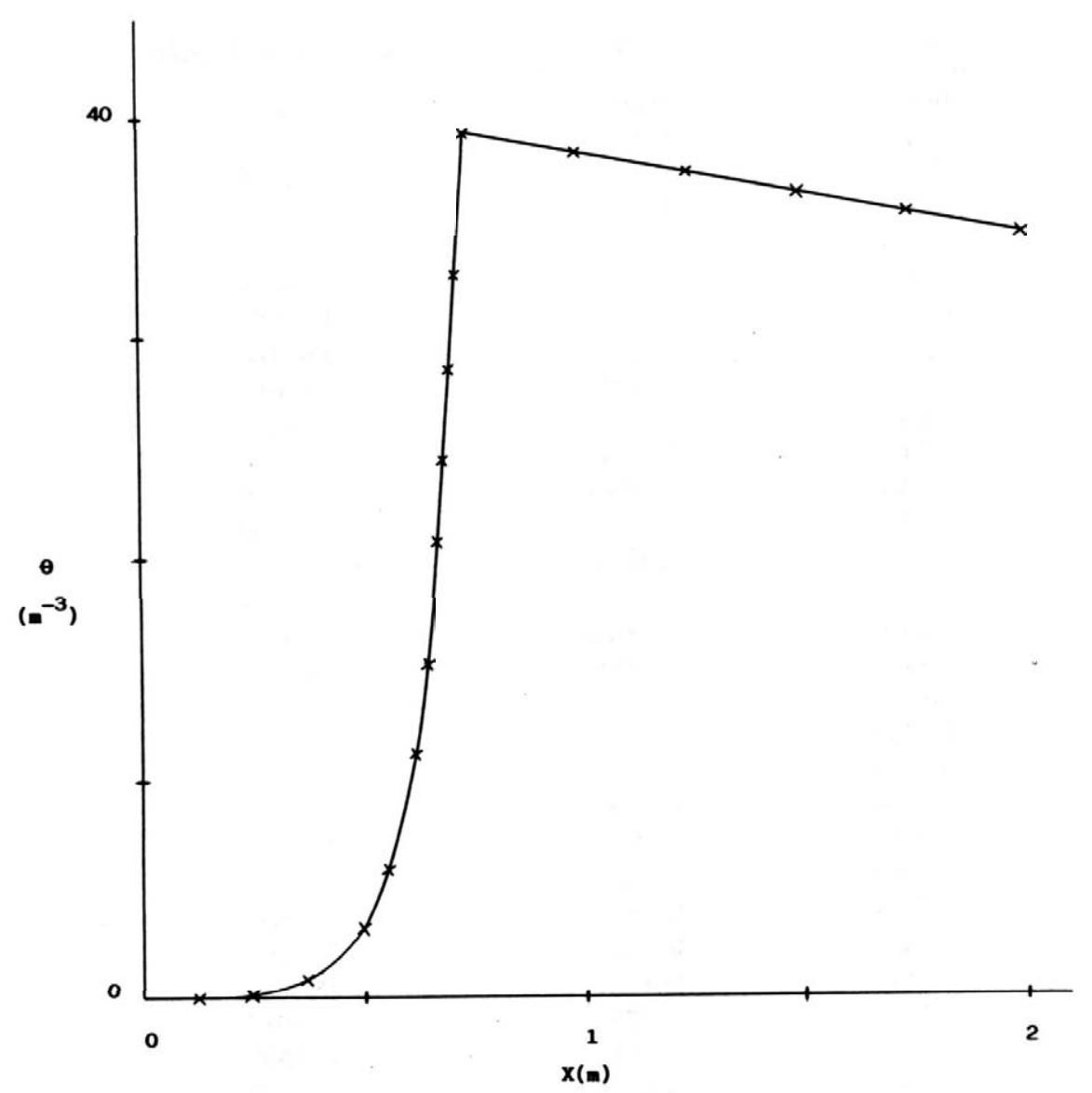

Fig. 5. Stationary solution. Discharge at $X=0.75 \mathrm{~m} ; \alpha=0.01 \mathrm{~s}^{-1} ; D_{x}=0.01 \mathrm{~m}^{2} \mathrm{~s}^{-1}$; $(u, v)=(0 \cdot 01,0 \cdot 0) \mathrm{m} \mathrm{s}^{-1}$. 
The stationary solution for $\alpha=0.01 \mathrm{~s}^{-1}$ is given in Fig. 5. The comparison of the numerical solutions with the exact ones show relative differences smaller than $4 \%$.

In the transitory case, the concentration changes with time for different values of $\Delta t$ and $\alpha$ have been obtained. An initial zero concentration was assumed. Table 4 shows the good agreement between the computed values and those given by the exact analytical solution.

TABLE 4

Solution for $t=6 \mathrm{~s}$ and $\Delta t=1.0 \mathrm{~s}$

\begin{tabular}{|c|c|c|}
\hline \multicolumn{3}{|c|}{ Transitory case, Decay coefficient $=0.01 \mathrm{~s}^{-1}$} \\
\hline Position $X(m)$ & $F E$ solution $\theta\left(\rho_{1} / \rho\right)$ & Exact solution $\theta\left(\rho_{1} / \rho\right)$ \\
\hline 0.0000 & 0.0000 & 0.0201 \\
\hline $0 \cdot 1250$ & 0.0839 & 0.0721 \\
\hline $0 \cdot 2500$ & 0.3475 & $0 \cdot 2515$ \\
\hline $0 \cdot 3750$ & $0 \cdot 8805$ & $0 \cdot 8888$ \\
\hline $0 \cdot 5000$ & $3 \cdot 1781$ & $3 \cdot 1409$ \\
\hline $0 \cdot 5625$ & $5 \cdot 8745$ & 5.9044 \\
\hline 0.6250 & $11 \cdot 0581$ & 11.0993 \\
\hline 0.6563 & $15 \cdot 1591$ & $15 \cdot 2180$ \\
\hline 0.6875 & $20 \cdot 7973$ & $20 \cdot 8651$ \\
\hline 0.7032 & $24 \cdot 3676$ & $24 \cdot 4377$ \\
\hline $0 \cdot 7188$ & $28 \cdot 5494$ & $28 \cdot 6220$ \\
\hline 0.7344 & 33.4285 & $33 \cdot 5058$ \\
\hline 0.7500 & $39 \cdot 1442$ & $39 \cdot 2230$ \\
\hline 0.7657 & $39 \cdot 0816$ & $39 \cdot 1625$ \\
\hline 0.7813 & $39 \cdot 0213$ & $39 \cdot 1019$ \\
\hline 0.7970 & $38 \cdot 9618$ & $39 \cdot 0415$ \\
\hline $0 \cdot 8125$ & $38 \cdot 9010$ & $38 \cdot 9813$ \\
\hline $0 \cdot 8438$ & $38 \cdot 7809$ & $38 \cdot 8609$ \\
\hline $0 \cdot 8750$ & $38 \cdot 6611$ & $38 \cdot 7408$ \\
\hline 0.9375 & $38 \cdot 4225$ & $38 \cdot 5018$ \\
\hline 1.0000 & $38 \cdot 1855$ & $38 \cdot 2642$ \\
\hline $1 \cdot 1250$ & $37 \cdot 7936$ & $37 \cdot 7936$ \\
\hline $1 \cdot 2500$ & $37 \cdot 3287$ & $37 \cdot 3287$ \\
\hline $1 \cdot 3750$ & $36 \cdot 8695$ & $36 \cdot 8695$ \\
\hline $1 \cdot 5000$ & $36 \cdot 4160$ & $36 \cdot 4160$ \\
\hline 1.6250 & $35 \cdot 9681$ & $35 \cdot 9681$ \\
\hline 1.7500 & $35 \cdot 5287$ & $35 \cdot 5287$ \\
\hline 1.8750 & $35 \cdot 0887$ & $35 \cdot 0887$ \\
\hline $2 \cdot 0000$ & $34 \cdot 6571$ & $34 \cdot 6571$ \\
\hline
\end{tabular}




\section{APPLICATION TO THE BAY OF SANTANDER}

The transport model has been applied to the Santander Bay (Spain), assuming different types of pollutant sources.

The geometry of the Santander Bay is shown in Fig. 6. A sea depth of $3 \mathrm{~m}$ was assumed.

The FEM mesh used in this study is composed of 369 LST elements and 857 nodes. The band width of the mesh is 54 . In Fig. 6 , the velocity at different nodes is also given.

The effect of the input of a pollutant with $\alpha=0 \mathrm{~s}^{-1}$ and concentration $\theta=1$ at the Ria de Astillero during a tidal period has been studied. The

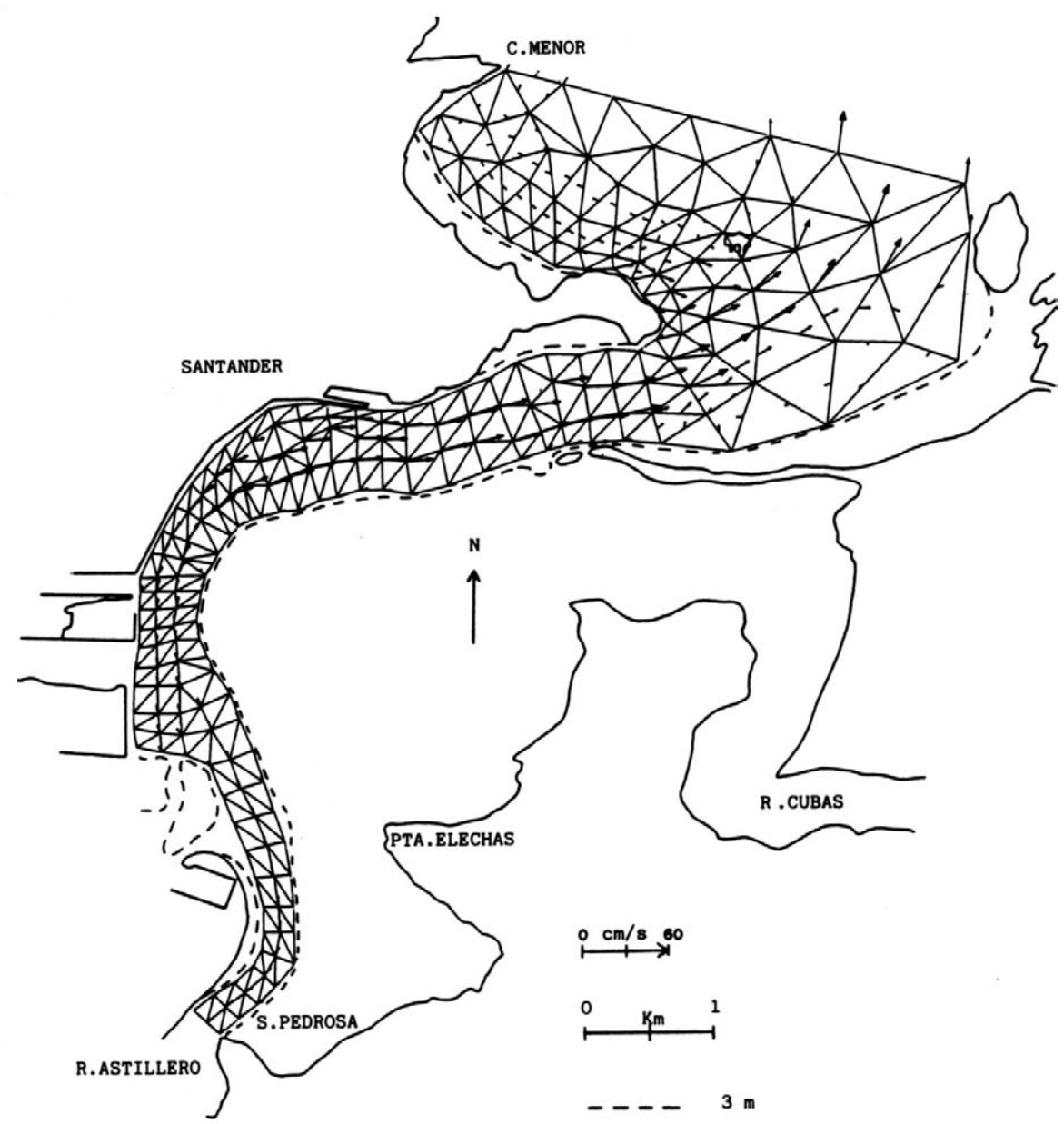

Fig. 6. Bay of Santander. 
assumed dispersivities have been $D_{x}=D_{y}=10^{3} \mathrm{~m}^{2} \mathrm{~s}^{-1}$ and the time interval $\Delta t=200 \mathrm{~s}$.

The concentration $\theta$ is represented by isolines at different times (Fig. 7 corresponds to $t=12 \mathrm{~h}$ ). It is seen that a more uniform concentration distribution in the outlet of the Bay, with the values near $0 \cdot 2$, applies.

Other situations have been considered, particularly the anisotropic case with different time steps $\Delta t$. It is necessary to increase mesh refinement for values of the dispersion coefficients $<5 \mathrm{~m}^{2} \mathrm{~s}^{-1}$.

The acceptable concentration level of a given pollutant is subject to discussion. However, the distribution of concentration can provide

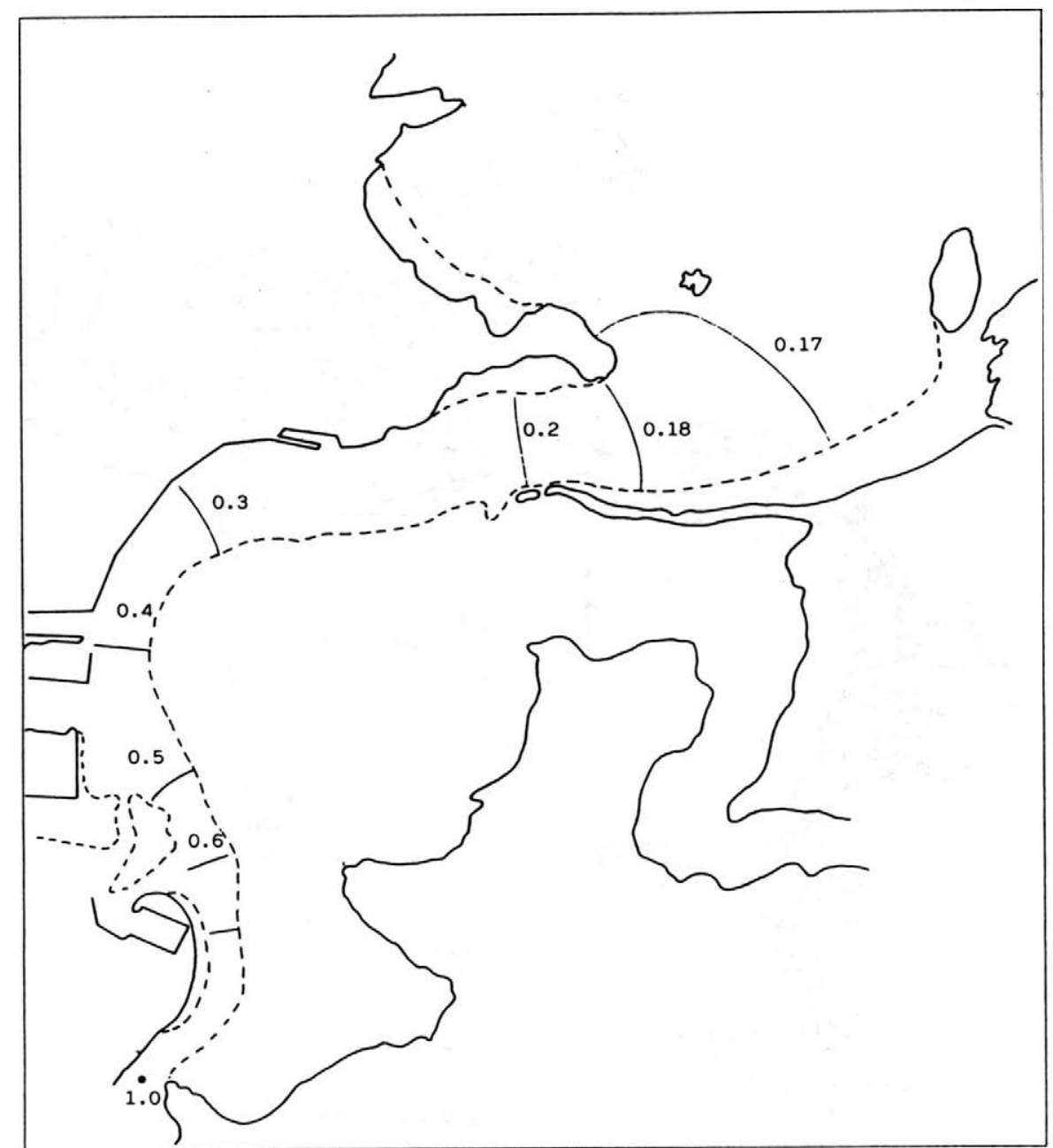

Fig. 7. Concentration contour with flood tide, for $t=12 \mathrm{~h}\left(\theta=\rho_{1} / \rho\right) ; D_{x}=D_{y}=$ $10^{3} \mathrm{~m}^{2} \mathrm{~s}^{-1} ; \Delta t=200 \mathrm{~s}$. 
some indication of the amount of dilution and purification which can take place between the source and a certain point.

\section{REFERENCES}

1. Lam, D. C. L., Comparison of finite element and finite difference methods for nearshore advection-diffusion transport models. Finite Elements in Water Resources, Pentech Press, Plymouth, UK, 1977.

2. McBride, G. B., Numerical solutions of the equations governing submarine discharge of liquid waste. Int. Conf. on Num. Meth. in Fluid Dynamics, Pentech Press, London, 1973, pp. 494-511.

3. Pritchard, D. W., Dispersion and flushing of pollutants in estuaries, Journal of the Hydraulics Division, ASCE, 95, No. HY1, 1969.

4. Andres, A. \& Cubillo, F., Calidad de las aguas superficiales 'Modelos simplificados', Direccion General de Recursos Hidráulicos, Vol. 6, 1984.

5. Barrett, M. J., Blanchard, M. J., Dempster, D. K., Mollowney, B. M. \& Rabone, D. J., Effect of polluting discharges on Ria de Bilbao. Report of Studies on Behalf of Ingenieria de la Polución, SA Water Research Centre, Stevenage, 1977.

6. Lager, J. A., Effluent disposal in South San Francisco Bay, Journal of the Sanitary Engineering Division, ASCE, Vol. 94, No. SA2, 1968.

7. Bailey, T. E., McCullough, C. A. \& Gunnerson, C. G., Mixing and dispersion studies in San Francisco Bay, Journal of the Sanitary Engineering Division, ASCE, 92, No. SA5, 1966.

8. Fischer, H. B., Dispersion predictions in natural streams, Journal of the Sanitary Engineering Division, ASCE, 94, No. SA5, 1968.

9. Cunge, J. A., Holly, F. M. Jr \& Schwartz, S., Mathematical modelling study of pollution transport in the Bay of Saint Brieuc (France). SOGREAGH, Ingenieurs Conseils, 1981.

10. Fischer, H. B., The mechanics of dispersion in natural streams, Journal of the Hydraulics Division, ASCE, 93, No. HY6, 1967.

11. Holley, E. R., Unified view of diffusion and dispersion, Journal of the Hydraulics Division, ASCE, 96, No. HY2, 1969.

12. Apelt, C. J., Gout, J. J. \& Szewczyk, A. A., Numerical modelling of pollutant transport and dispersion in bays and estuaries. Int. Conf. on Num. Meth. in Fluids Dynamics, Pentech Press, London, 1973, pp. $307-24$.

13. Baker, A. J., A highly stable explicit integration technique for computational continuous mechanics. Int. Conf. on Num. Meth. in Fluids Dynamics, Pentech Press, London, 1973 pp. 99-120.

14. Bella, D. A. \& Dobbins, W. E., Difference modelling of stream pollution, Journal of the Sanitary Engineering Division, ASCE, 94, No. SA5, 1968.

15. Ehlig, C., Comparison of numerical methods for solution of the diffusion convection equation in one and two dimensions. Finite Elements in Water Resources. Pentech Press, Plymouth, UK, 1977.

16. Brebbia, C. A. \& Adey, R., Circulation problems. Dept of Civil Engineering, Univ. of Southampton, UK 1977. 
17. Zienkiewicz, O. C. \& Morgan, K., Finite Elements and Approximation, John Wiley and Sons, New York, 1983.

18. Kashiyama, K., Interpolation method for preparation of input data of water depth in finite element analysis of shallow water flow, Eng. Comput., 2, Dec. (1985) 266-70.

19. Pritchard, D. W., Estuarine Modelling: An Assessment, ed. G. W. Ward, Jr \& W. H. Epsey, Jr, Nat. Tech. Inform Serv. Publ., New York, 1971.

20. Pinder, G. F. \& Gray, W. G., Finite Elements Simulation in Surface and Subsurface Hydrology, Academic Press, New York, 1977.

21. Smith, I. A., Integration in time of diffusion and diffusion convection equations. Finite Elements in Water Resources. Pentech Press, Plymouth, UK, 1977.

22. Bathe, K. J. \& Wilson, E. L., Numerical Methods in Finite Element Analysis, Prentice Hall, New York 1976.

23. Stoer, H. R. \& Bulirsch, R., Introduction to Numerical Analysis. Springer Verlag, New York, 1980. 